WellBeing International

WBI Studies Repository

$11-2009$

\title{
Assessing Animal Welfare: Different Philosophies, Different Scientific Approaches
}

David Fraser

University of British Columbia

Follow this and additional works at: https://www.wellbeingintlstudiesrepository.org/assawel

Part of the Animal Studies Commons, Other Animal Sciences Commons, and the Other Anthropology Commons

\section{Recommended Citation}

Fraser, D. (2009). Assessing animal welfare: different philosophies, different scientific approaches. Zoo Biology, 28(6), 507-518.

This material is brought to you for free and open access by WellBeing International. It has been accepted for inclusion by an authorized administrator of the WBI Studies Repository. For more information, please contact wbisr-info@wellbeingintl.org.

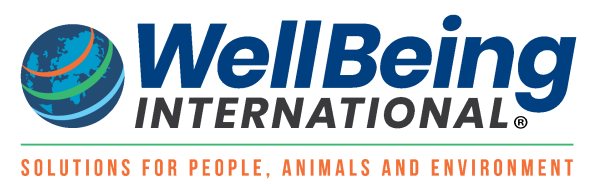




\title{
Assessing Animal Welfare: Different Philosophies, Different Scientific Approaches
}

\author{
David Fraser
}

University of British Columbia

\author{
KEYWORDS \\ animal welfare, health, animal behavior, affect
}

\begin{abstract}
Attempts to improve animal welfare have commonly centered around three broad objectives: (1) to ensure good physical health and functioning of animals, (2) to minimize unpleasant "affective states" (pain, fear, etc.) and to allow animals normal pleasures, and (3) to allow animals to develop and live in ways that are natural for the species. Each of these objectives has given rise to scientific approaches for assessing animal welfare. An emphasis on health and functioning has led to assessment methods based on rates of disease, injury, mortality, and reproductive success. An emphasis on affective states has led to assessment methods based on indicators of pain, fear, distress, frustration and similar experiences. An emphasis on natural living has led to research on the natural behavior of animals and on the strength of animals' motivation to perform different elements of their behavior. All three approaches have yielded practical ways to improve animal welfare, and the three objectives are often correlated. However, under captive conditions, where the evolved adaptations of animals may not match the challenges of their current circumstances, the single-minded pursuit of any one criterion may lead to poor welfare as judged by the others. Furthermore, the three objectives arise from different philosophical views about what constitutes a good life-an area of disagreement that is deeply embedded in Western culture and that is not resolved by scientific research. If efforts to improve animal welfare are to achieve widespread acceptance, they need to strike a balance among the different animal welfare objectives.
\end{abstract}

\section{INTRODUCTION}

In 1964, the Vancouver Aquarium commissioned a local sculptor to kill an orca. The plan was that the sculptor, who had also worked as a commercial fisherman, would harpoon an orca and then use the animal's carcass to make a lifelike replica as part of the Aquarium's educational display.

The project did not go as planned. Amid great attention from the media, the sculptor set up a harpoon gun on an island where orcas were known to pass, but for two months few orcas came into view. Finally, well after public interest had died down, the Aquarium received an urgent telephone call. The sculptor had harpooned an orca; it was struggling vigorously on the harpoon line; but it showed no sign of expiring. A quick decision was made to use the harpoon line to tow the orca the $60 \mathrm{~km}$ to a temporary holding facility 
in the port of Vancouver, and there the orca suddenly became an international celebrity. An estimated 20,000 people flocked to see it on the first day when public viewing was allowed. Stories about it appeared in Time, Newsweek, Life, The New York Times and a host of other publications. A film about the orca and its capture was shown in 43 countries [Newman, 1993].

The orca died after only 75 days, but the public interest was so great that the Aquarium then built a large orca tank, and for the next 30 years wild-caught orcas were the star attractions of the Aquarium.

By the 1990s, however, the Aquarium found itself facing increasing pressure from critics, the media and some of their own paying customers who questioned the ethics of keeping orcas in captivity. Surely, the critics argued, such an intelligent and social animal must live a miserable and unhealthy life swimming in a concrete tank for the amusement of spectators. After a lengthy debate, the Aquarium decided that it would no longer keep wild-caught orcas, and the last one was transferred to a facility in San Diego where she would at least have more space and the company of other orcas.

The story of the Vancouver orcas is just one of many events that illustrate the tremendous change that has taken place during the last few decades in the level of public interest in animals and their welfare-a change from a time when killing an orca to make a replica of its carcass seemed like a reasonable idea, to a time when an institution might decide, for reasons of animal welfare, to refrain from keeping such animals in captivity at all.

In this essay I trace a little of the background and history of the issue. First I describe the debate that arose over the nature of animal welfare, and then some of the scientific approaches and practical applications of animal welfare science. Finally I comment on the interplay of values and empirical investigation that we encounter in the scientific assessment of animal welfare.

\section{DIFFERENT VIEWS OF ANIMAL WELFARE}

The changing views about animals and their welfare exerted a profound influence on almost all aspects of animal use: in zoos and aquaria, in biomedical research, in wildlife management and perhaps especially (given the enormous numbers of animals involved) in animal agriculture.

In fact, in the same year that Vancouver sculptor harpooned the unfortunate orca, a mild-mannered English vegetarian named Ruth Harrison launched a much more effective attack on modern animal production. The attack was her book Animal Machines [Harrison, 1964] in which she shocked readers with descriptions of the living conditions of chickens, pigs and veal calves in the confinement production systems that were then becoming common. The book created such a commotion in the United Kingdom that the government felt compelled to act. The result was a body of hearings, legislation and research focused on the welfare of animals kept in confinement.

The book also touched off an extensive debate on an issue that had never been resolved: what exactly is meant by "animal welfare"? As the discussion unfolded, it soon became clear that different people were using the term to capture somewhat different concerns about the quality of life of animals.

Mrs. Harrison herself expressed one kind of concern. She claimed that confinement housing is so unsuited to animals that they inevitably lead miserable lives. In one passage she asked:

"How far have we the right to take our domination of the animal world? Have we the right to rob them of all pleasure in life simply to make more money more quickly out of their carcasses?" 
Later, in his influential book Animal Liberation, Australian philosopher Peter Singer [1990] based his criticisms of the treatment of animals on the principle that actions should be judged right or wrong on the basis of the pain or pleasure that they cause. He claimed:

"There can be no moral justification for regarding the pain (or pleasure) that animals feel as less important than the same amount of pain (or pleasure) felt by humans."

In these and many other quotations we see a cluster of concerns centered on states like "pleasure," "pain," "suffering" and "happiness," which together make up the "affective states" of animals-that is, emotions and other feelings that are experienced as either pleasant or unpleasant rather than hedonically neutral.

In discussing the confinement of animals, however, some people put the emphasis elsewhere. The British committee [Brambell, 1965] formed in the wake of Animal Machines to conduct hearings on the subject concluded:

"In principle we disapprove of a degree of confinement of an animal which necessarily frustrates most of the major activities which make up its natural behaviour."

Astrid Lindgren, the famous author of the Pippi Longstocking stories and a driving force behind animal welfare reform in Sweden, proposed:

"Let [farm animals] see the sun just once, get away from the murderous roar of the fans. Let them get to breathe fresh air for once, instead of manure gas." [Anonymous, 1989].

And American philosopher Bernard Rollin [1993] insisted that we need:

"...a much increased concept of welfare. Not only will welfare mean control of pain and suffering, it will also entail nurturing and fulfilment of the animals' natures..."

In these quotations, although affective states were often involved implicitly or explicitly, the central concern was for a degree of "naturalness" in the lives of animals: that animals should be able to perform their natural behavior, that there should be natural elements in their environment, and that we should respect the "nature" of the animals themselves.

All the above quotations reflected the views of social critics and philosophers, but farmers and veterinarians brought a different focus to the discussion of animal welfare. For example, one veterinarian [Taylor, 1972] argued that the welfare of animals is actually improved by confinement systems because:

"On balance I feel that the animal is better cared for; it is certainly much freer from disease and attack by its mates; it receives much better attention from the attendants, is sure of shelter and bedding and a reasonable amount of good food and water."

Or as the veterinary educator David Sainsbury [1986] put it:

"Good health is the birthright of every animal that we rear, whether intensively or otherwise. If it becomes diseased we have failed in our duty to the animal and subjected it to a degree of suffering that cannot be readily estimated."

Here the primary emphasis is on the fairly traditional concerns of veterinarians and animal producers that animals should have freedom from disease and injury, plus food, water, shelter and other necessities of life-concerns that we might sum up as the basic physical health and functioning of the animals. 
In these various quotations, then, we see various concerns that can be grouped roughly under three broad headings: one centers on the affective states of animals, one on the ability of animals to lead reasonably natural lives, and one emphasizes basic health and functioning. These are not, of course, completely separate or mutually exclusive. For example, Harrison and Lindgren clearly believed that allowing animals to live a more natural life would make them more happy and healthy, and Sainsbury clearly believed that unhealthy animals would suffer.

Nonetheless, the different areas of emphasis are sufficiently independent that they can lead to quite different actions. A veterinarian may want animals kept individually in sterile cages to isolate them from disease, while an animal behavior scientist wants an enriched group enclosure so that animals can behave more naturally, and both claim to be promoting animal welfare. Or an organic farmer may insist that animals have better welfare in a free-range system because it is more natural, while a confinement farmer insists that animals are better off indoors where they are protected from storms and predators.

These are not, of course, factual disagreements: the veterinarian and the animal behaviorist, the organic farmer and the confinement producer, all may agree on the factual issues such as the mortality rate, whether the animals can perform certain behavior and whether a particular veterinary procedure causes pain. The disagreement stems from different values-from different views about what is most important for animals to have a good life.

\section{ANIMAL WELFARE AND SCIENCE}

As these disagreements began to surface, many people thought that the emerging body of animal welfare research would provide a solution in the form of an objective, value-free, scientific assessment of animal welfare that would make the value-based disagreements irrelevant. What actually happened proved to be much more interesting.

\section{Basic Health and Functioning}

Some scientists, adopting the tools of veterinary pathology, epidemiology and related fields, used the basic health and functioning of animals as a basis for assessing and improving animal welfare. As one example, Ragnar Tauson and co-workers in Sweden improved the welfare of laying hens by studying the injuries incurred by hens in commercially available cages of different designs. The research showed that the birds developed foot lesions if the floor was sloped too steeply, and neck lesions if the feed trough was too deep and installed too high for comfortable access. There was often feather damage that could be reduced by the use of solid side partitions, and overgrown claws that could be prevented by installing abrasive strips. Thus, just by focusing on physical health it was possible to make large improvements in the welfare of the birds, and these results formed the basis of the early regulations on cage design in Sweden and later in the European Union [Tauson, 1998].

In other cases, scientists used simple measures of survival and reproduction to identify problems. In the 1980s, Adams and Craig [1985] did an analysis of 30 studies that had recorded survival and egg production by hens kept in cages at different commercial stocking rates. The results showed that moving from relatively spacious cages (averaging $516 \mathrm{~cm}^{2}$ per bird) to medium density $\left(387 \mathrm{~cm}^{2}\right.$ ) resulted in the mortality rate during a laying cycle rising by $1.4 \%$, and the birds produced about eight fewer eggs. Increasing further from medium to very crowded cages (averaging only $310 \mathrm{~cm}^{2}$ per bird) resulted in the mortality rate rising by an extra $4.8 \%$ and production falling by an additional 17 eggs. This study did not result in the adoption of animal welfare standards at the time, but 20 years later a similar review drew similar conclusions, and the egg industry in the United States adopted animal welfare guidelines based on the findings [UEP, 2008]. 
Epidemiological studies of disease incidence on different farms have also played an important role in improving animal welfare. A classic example was a 5-year study by epidemiologist Ingvar Ekesbo [1966] who compared the incidence of common diseases on Swedish dairy farms in the 1960s. Ekesbo found, for example, that "milk fever", a metabolic disorder caused by a severe drop in blood calcium level just after calving, was slightly less common when the cows were indoors rather than on pasture, perhaps because farmers could exert better control over the animals' mineral intake while they were confined. Trampled teats followed the opposite pattern. This problem rarely occurred while cows were on pasture, but it was common if the cows spent the day tied in individual stalls. Mastitis (inflammation of the udder) followed a different pattern again. It was about twice as common on farms where the cattle had to lie on hard surfaces (usually concrete) compared with farms where the resting area was bedded in straw or sawdust. Ekesbo's study provided invaluable guidance to dairy producers during a time when the industry was experimenting with various forms of housing. It also served as a precursor to modern multi-institution studies that use differences between zoos to identify likely causal factors for problems such as reproductive failure [Mellen, 1991] or evidence of stress [Wielebnowski et al., 2002].

\section{Natural Living Approaches}

Fifty years ago the American psychologist Harry F. Harlow wanted to create a colony of disease-free monkeys for research purposes. To do this Harlow separated newborn monkeys from their mothers and raised them in individual cages where they could see other monkeys but were otherwise isolated from pathogens. The method produced monkeys with excellent physical health, but as the animals matured Harlow realized that they were, in his words, "emotionally disturbed":

"As a group they exhibit abnormalities of behavior rarely seen in animals born in the wild and brought to the laboratory as preadolescents or adolescents, even after the latter have been housed in individual cages for many years. The laboratory-born monkeys sit in their cages and stare fixedly into space, circle their cages in a repetitive stereotyped manner and clasp their heads in their hands or arms and rock for long periods of time." [Harlow and Harlow, 1962.]

In cases such as these, we see obvious animal welfare problems arising when animals are kept under highly unnatural conditions. Hence it is no surprise that many scientists have tried to improve animal welfare by making living conditions more natural.

A well known example was the work of Stolba and Wood-Gush [1984] who began a project on improved pig housing by observing pigs living freely in a hilly, wooded area. They found that the pigs showed certain characteristic types of behavior: they rooted in the soil, exercised their neck muscles by levering against fallen logs, built nests in secluded areas before giving birth and used dunging areas well removed from their resting areas. Stolba and Wood-Gush then designed a complex commercial pen that allowed the animals to behave in these ways. It included an area with peat moss for rooting, logs for levering, a separate dunging area, and secluded areas where sows could build nests before parturition. The authors claimed that the animals' welfare was much improved by the complex pen. However, because some aspects of basic health (especially neonatal survival) were not as good in this system as in well run confinement systems, some people disagreed with that conclusion [Edwards, 1995].

In less radical approaches, scientists have incorporated simple elements of natural behavior into existing rearing systems. On many commercial dairy farms, calves are separated from their mothers soon after birth, and are then fed milk from a bucket, usually twice per day. With such infrequent meals the total intake is normally limited so that the calf does not receive too much milk at one time. Under natural conditions, cows stay near their calves for the first two weeks, and the calf will feed many times per day in 
smaller meals. Although it is normally not practical to leave dairy calves with the cow, feeding systems can still be made to correspond more closely to the animals' natural behavior. If the calves are fed more frequently, then they can drink more milk per day without developing digestive problems; and if the calves suck from an artificial teat rather than drinking from a pail, the action of sucking may lead to a greater release of certain digestive hormones [de Passillé et al., 1993]. As might be expected, therefore, calves fed frequently by teat gain substantially more weight than calves fed twice daily by bucket [Appleby et al., 2001].

In these examples, accommodating "natural" behavior helped to solve certain animal welfare problems. However, the natural behavior of animals falls roughly into two categories: things that the animal wants to do and things that the animal would rather not do. For example, pigs seem very eager to root in the soil and to find nesting places, but presumably they would rather not shiver from cold or flee from predators, even though those, too, are elements of "natural" behavior. When confronted with a particular type of natural behavior, how can we determine which type it is?

An obvious approach is to ask the animals themselves. Hens, for example, can be trained to perform a simple task, such as pecking on a key, for a reward such as food. They will also learn to perform similar responses for other rewards such as warmth or additional space in their cages. With such methods it can be shown that hens are highly motivated to obtain a perch where they can rest at night, a nest box where they can retreat to lay eggs and litter for dust bathing and feather care. It was largely on the basis of such evidence that the European Union's current directive on the welfare of hens requires that the birds be provided with a perch, a nest-box and litter when the standard ("battery") cage is phased out in 2012 [Appleby et al., 2002].

In summary, in light of the welfare problems that can arise under highly unnatural conditions, an intuitively appealing solution is to try to create more "natural" rearing conditions; however, the approach requires analysis. As a rough approximation, we can think of a two-by-two table: behavior may be either natural or not natural for the species, and it may be either preferred or not preferred by the individual. In general, animal welfare is most likely to be improved by accommodating behavior that is both natural and preferred; examples include calves feeding multiple times per day and hens resting on a perch at night. Welfare may not be improved by accommodating behavior that is natural but not preferred (shivering in the cold, fleeing from predators) or preferred but not natural (eating rich foods). These approaches in the study of farm animals have, of course, many parallels in the study of zoo animals, especially in the areas of "environmental enrichment" [Shepherdson et al., 1998] and "behavioral enrichment" [Markowitz, 1982].

\section{Affective States}

In other cases, scientists have based animal welfare research on the affective states of animals. The research to date has followed several distinct strategies.

In some cases, animals are thought to have signals that communicate particular affective states to other animals, and research has used the signals as a means of identifying, and to a degree quantifying, the affective states. For example, if an unweaned piglet becomes separated from its mother, its behavior follows a typical sequence. The piglet begins by walking slowly and giving short, quiet grunts separated by a second or two of silence. If the piglet does not find the mother, its movements gradually become more rapid, the calling becomes louder and more frequent, and the calls change gradually to high-pitched squeals. Experiments have shown that newly separated piglets give more calls, especially more of the loud, high-pitched calls, if they have not been fed recently or if they are in a cool environment; both of these are conditions that presumably increase their need to be re-united with the mother. Moreover, when 
the calls are played through a hidden speaker, sows approach the speaker, and they respond more vigorously to calls given by piglets in conditions of greater need [Weary et al., 1997]. The working hypothesis in this case is that piglets experience a type of "separation distress" when separated from the mother under conditions that would threaten their survival in the wild, and that the calls communicate this affective state to the mother. Thus (we assume) we can use the calls to identify, and assess the intensity of, this affective state [Weary and Fraser, 1995].

In cases where animals do not signal an affective state, the state may still be accompanied by some characteristic behavior or other change. For example, if a chicken is held firmly for about $15 \mathrm{sec}$ on its back or side and then released, the chicken is likely to remain immobile for many seconds or minutes in a reaction commonly called "tonic immobility" or "death-feigning" [Jones, 1996]. Tonic immobility is viewed as an indicator of fear, partly because it occurs in situations that might cause fear, partly because procedures intended to calm the birds (tranquillizers and habituation) reduce the response, and partly because tonic immobility persists longer if chickens have just been exposed to loud noises or other events intended to create fear [Jones, 1986].

An interesting application of tonic immobility as an index of fear occurred in a debate about how to minimize fear when chickens are caught to be shipped for slaughter. Traditionally chickens are caught by crews of people who grab birds by the legs and carry them upside-down to the shipping crates. A newer alternative is the mechanical "chicken harvester"-a large machine that moves slowly through the building, gathers up birds in a set of rotating rubber fingers, and transfers them to the crates by a conveyor belt. When mechanical harvesters first appeared, there was concern that they would cause fear and panic in the birds. However, in a comparison of the catching methods, Duncan et al. [1986] found that birds remained in tonic immobility for significantly less time after machine catching than after manual catching. This and other evidence suggested that machine catching actually caused less fear.

In other cases we may gain indirect evidence of affective states from nonspecific changes in either behavior or physiology. Many dairy calves have their horn-buds removed so that the horn will not develop and become a threat to the safety of other animals and farm workers. The "scoop" method of disbudding is done with two joined, semi-circular blades, which close around the horn-bud and cut it away, together with adjacent skin and some underlying bone. A research team in New Zealand, wanting to test workable methods of pain reduction, used plasma levels of the stress-related hormone cortisol to quantify the pain of disbudding. They monitored plasma cortisol levels for three groups of calves: those that were disbudded without any form of pain management, those that received local anesthetic to numb the area beforehand, and a sham control group that were handled in a similar manner but not actually disbudded. The disbudding was quickly followed by a large increase in plasma cortisol if the procedure was done without local anesthetic, but the use of local anesthetic largely prevented the cortisol response. This finding, combined with the lack of a cortisol response in the sham controls, which were handled in the same way but not disbudded, made a very plausible case that the cortisol response in this situation served as an indirect indicator of the pain caused by the procedure [Petrie et al., 1996].

\section{DIFFERENT CRITERIA OF ANIMAL WELFARE}

The different scientific approaches described above often lead to much the same conclusions. Allowing pigs to wallow in mud on a hot day is likely to improve their welfare by all three criteria: because the pigs will feel more comfortable (an affective state criterion), because their body processes will be less disrupted by heat stress (a basic health/functioning criterion) and because they can perform their natural thermoregulatory behavior (a natural living criterion). 
There is a certain evolutionary logic to this convergence of the criteria. We think of a given species of animal as being adapted to live in a certain type of environment with certain physical features, certain types of food, certain social groupings and so on; and we expect a species to have evolved adaptations that allow its members to thrive in such an environment. Conversely, we expect that animals may fail to thrive in very different environments for which they lack adaptations. Therefore, putting animals in situations that are natural for the species-where they can use their behavioral adaptations-should in general help to promote good health and functioning. And inasmuch as affective states are also evolved adaptations that motivate animals to do what is beneficial and avoid what is harmful [Broom, 1998; Dawkins, 1998; Fraser and Duncan, 1998], then affective states should also be linked to the health and functioning of animals.

Nonetheless, there are many cases where the single-minded pursuit of any one criterion may fail to improve animal welfare as defined by the others. From Harlow's monkeys we found that a housing system designed solely to promote physical health led to animals that had very unnatural and seemingly unhappy lives. Various studies of unconfined rearing systems for farm animals show that animals may have plenty of fresh air and freedom to perform their natural behavior, but may also be challenged by diseases and parasites that could be better controlled in more artificial conditions [Nordenfors and Höglund, 2000]. A focus on affective states is no panacea either. Well fed Labrador Retrievers may never suffer from hunger but are likely to develop heart problems from being over-weight [Lawler et al., 2005].

Many of these conflicts occur when animals are kept under artificial conditions where their natural behaviour and affective states may no longer lead to the beneficial consequences that they had in the environment where the species evolved. We can distinguish at least three types of problems. First, animals may be highly motivated to carry out behavior that no longer serves any important role for basic health. In the wild, for example, a rodent may escape from aerial predators by hiding in a burrow; in a protected, captive environment the animal may still be strongly motivated to use a burrow, and distressed if it cannot, even though the behavior is no longer needed for survival. Second, a motivation that was beneficial for health in the wild may prove detrimental under artificial conditions. For example, a tendency to favor sweet foods may be adaptive in a natural environment where energy-rich foods are rare, but it may lead to obesity among captive animals if such foods are easy to obtain. And third, unnatural benefits such as vaccination or deworming may be feared and resisted by the animal even though they are good for its health. In all these cases, the kinds of artificial conditions that are virtually inevitable in captivitydifferent environments, different access to food, health care-create a degree of disconnection between the animal's natural behavior, its affective states and its basic health and functioning.

In summary, once we depart from circumstances in which the animals' adaptations evolved, we may see a certain uncoupling between the different criteria of animal welfare, and the single-minded pursuit of any one criterion may not promote good animal welfare as judged by the others. Under these conditions, judgement is needed to balance the different benefits and to seek options that address all three types.

\section{ANIMAL WELFARE SCIENCE AND VALUES}

Each of the different scientific approaches has led to important practical improvements in animal welfare: cages that do not cause injuries, housing systems that reduce disease and distress, feeding systems that match natural meal size and frequency, handling methods that reduce fear and so on.

Contrary to early hopes, however, the science did not replace the different value-based views of welfare by providing a single, objective approach. In fact, the different value-based views were actually adopted by scientists and provided some of the richness of the scientific work. 
At one level, this should come as no surprise. The different value-based views are deeply embedded in Western culture, as we can see in many centuries of philosophical debate about what constitutes a "good life" for humans [Fraser, 2008]. Is a good life a hedonically pleasant life wherein pleasures predominate and pains are at a minimum? Or is a good life a natural life that is lived in harmony with nature, unconstrained by the artificiality of human conventions and technology? Or is a good life a healthy and productive life where the rational application of science and technology helps overcome the vicissitudes of nature? Given such diversity over one of the fundamental question of philosophy, it is not surprising that a similar diversity would arise when people judge what constitutes a good life for animals, and that scientists, as a diverse group influenced to varying degrees by the various currents of Western thought, should tacitly adopt these different ideas when deciding how to assess and improve animal welfare.

Nonetheless, the influence of values in animal welfare science may come as a surprise to those who have been taught to think of science as "value-free". During the 1800s, there was active debate about the boundaries separating science, philosophy and ethics. Sociologist Max Weber argued that science has a fact-finding role that helps to inform ethical decisions, but that science itself does not answer ethical or policy questions [e.g., Dahrendorf, 1987]. Such thinking obviously has merit, but in its crudest form it gave rise to the idea that values play no role in science. However, if a concept such as animal welfare can be both science-based and value-based, then clearly we need a more nuanced understanding of the place of values in science.

A partial solution is to regard animal welfare science as a type of "mandated science"-science that has been undertaken to guide actions, decisions and policy [Salter et al., 1988; Fraser, 2008]. Mandated science includes research on topics such as health, food safety and animal welfare. In all these cases, the science is done to understand concepts that incorporate notions of merit or worth. To say that health or safety or welfare has increased implies not merely a change but a change for the better. Hence, these concepts, while fully amenable to scientific research, inevitably rest on value-based beliefs about what is more or less desirable.

In the case of animal welfare, then, decisions can be based on a sound, scientific understanding of animals and how they are affected by housing, management procedures and health care measures. However, the data that we choose to collect when making decisions about animal welfare are determined in part by value-based ideas about what is important for animals to have a good life.

\section{IMPLICATIONS}

How, then, can we apply animal welfare science to animals in zoos? Clearly, various methods used in animal welfare science provide many avenues for improving the lives of zoo animals by improving basic health, by reducing states such as pain and fear, and by allowing animals to carry out types of behavior that are natural and preferred. However, the single-minded pursuit of any one criterion may fail to promote animal welfare as judged by the others. In deciding on a course of action, the different criteria of animal welfare need to be considered together. For actions to be widely accepted as achieving high animal welfare, in addition to being based on good science, they will need to take some account of the different value positions about what constitutes a good life for animals.

\section{CONCLUSIONS}

1. Concerns about the "welfare" of animals can be grouped roughly under three main headings: the basic health and functioning of animals, their affective states (pain, distress, etc.) and the ability of animals to live reasonably natural lives. 
2. Each of these clusters of concerns has given rise to scientific research methods designed to assess and improve animal welfare.

3. The various methods provide a wide range of means to improve animal welfare in practical ways—by preventing injuries and disease, by reducing pain and fear and by allowing animals to carry out behavior that they are motivated to perform.

4. The single-minded pursuit of any of the three concerns alone will not necessarily improve animal welfare as judged by the other criteria.

5.In implementing animal welfare practices or developing animal welfare standards, our efforts, in addition to being based on science, need to make a reasonable fit to the different views about what constitutes a good life for animals.

\section{ACKNOWLEDGMENTS}

This paper summarizes some ideas from my book Understanding Animal Welfare: The Science in its Cultural Context, published by Wiley-Blackwell, and from a lecture entitled "Understanding Animal Welfare" published in Acta Veterinaria Scandinavica 2008, 50 (Suppl 1), Article S1 (pages 1-7). I am grateful to the publishers and to the Universities Federation for Animal Welfare for permission to use some of that material here. Preparation of the paper was made possible by grants from the Natural Sciences and Engineering Research Council of Canada and the Social Sciences and Humanities Research Council of Canada. I am most grateful to the many colleagues, most notably Dan Weary and others in the Animal Welfare Program at the University of British Columbia, for the part they have played in the development of these ideas.

\section{REFERENCES}

Adams AW, Craig JV. 1985. Effect of crowding and cage shape on productivity and profitability of caged layers: a survey. Poult Sci 64: 238-242.

Anonymous. 1989. How Astrid Lindgren achieved enactment of the 1988 law protecting farm animals in Sweden. Washington: Animal Welfare Institute.

Appleby MC, Weary DM, Chua B. 2001. Performance and feeding behaviour of calves on ad libitum milk from artificial teats. Appl Anim Behav Sci 74:191-201.

ApplebyMC, Walker AW, Nicol CJ, Lindberg AC, Freire R, Hughes BO, Elson HA. 2002. Development of furnished cages for laying hens. Br Poult Sci 43:489-500.

Brambell FWR (chairman). 1965. Report of the technical committee to enquire into the welfare of animals kept under intensive livestock husbandry systems. London: Her Majesty's Stationery Office.

Broom DM. 1998. Welfare, stress, and the evolution of feelings. Adv Study Behav 27: 371-403.

Dahrendorf R. 1987. Max Weber and modern social science. In: Mommsen WJ, Osterhammel J, editors. Max Weber and his contemporaries. London: Allen \& Unwin. p 574-580.

Dawkins MS. 1998. Evolution and animal welfare. Q Rev Biol 73:305-328.

de Passillé AMB, Christopherson R, Rushen J. 1993. Nonnutritive sucking by the calf and postprandial secretion of insulin, CCK, and gastrin. Physiol Behav 54:1069-1073.

Duncan IJH, Slee G, Kettlewell P, Berry P, Carlisle AJ. 1986. Comparison of the stressfulness of harvesting broiler chickens by machine and by hand. Brit Poult Sci 27:109-114. 
Edwards SA. 1995. Designing systems to meet behavioral needs: the Family Pen system for pigs. In: Animal behavior and the design of livestock and poultry systems. Ithaca: Northeast Regional Agricultural Engineering Service p 115-125.

Ekesbo I. 1966. Disease incidence in tied and loose housed dairy cattle and causes. Acta Agric Scand 15:1-74.

Fraser D. 2008. Understanding animal welfare: the science in its cultural context. Oxford: Wiley-Blackwell.

Fraser D, Duncan IJH. 1998. Pleasures, pains and animal welfare: toward a natural history of affect. Anim Welf 7:383-396.

Harlow HF, Harlow MK. 1962. Social deprivation in monkeys. Sci Am 207:136-146.

Harrison R. 1964. Animal machines. London: Vincent Stuart Ltd.

Jones RB. 1986. The tonic immobility reaction of the domestic fowl: a review. Worlds Poult Sci J 42:8296.

Jones RB. 1996. Fear and adaptability in poultry: insights, implications and imperatives. Worlds Poult Sci J 52:131-174.

Lawler DF, Evans RH, Larson BT, Spitznagel EL, Ellersieck MR, Kealy RD. 2005. Influence of lifetime food restriction on causes, time, and predictors of death in dogs. J Am Vet Med Assoc 226:225-231.

Markowitz H. 1982. Behavioral enrichment in the zoo. New York: Van Nostrand Reinhold.

Mellen JD. 1991. Factors influencing reproductive success in small captive exotic felids (Felis spp.): a multiple regression analysis. Zoo Biol 10:95-110.

Newman MA. 1993. The history of the Vancouver Aquarium. Vancouver: Vancouver Public Aquarium Association.

Nordenfors H, Höglund J. 2000. Long-term dynamics of Dermanyssus gallinae in relation to mite control measures in aviary systems for layers. Br Poult Sci 41:533-540.

Petrie NJ, Mellor DJ, Stafford KJ, Bruce RA, Ward RN. 1996. Cortisol response of calves to two methods of disbudding used with or without local anaesthetic. NZ Vet J 44:9-14.

Rollin BE. 1993. Animal welfare, science, and value. J Agric Environ Ethics 6:44-50.

Sainsbury D. 1986. Farm animal welfare: cattle, pigs and poultry. London: Collins.

Salter L, Levy E, Leiss W. 1988. Mandated science: science and scientists in the making of standards. Dordrecht: Kluwer Academic Publishers.

Shepherdson DJ, Mellen JD, Hutchins M. 1998. Second nature: environmental enrichment for captive animals. Washington: Smithsonian Institution Press.

Singer P. 1990. Animal liberation, 2nd ed. New York: Avon Books.

Stolba A, Wood-Gush DGM. 1984. The identification of behavioural key features and their incorporation into a housing design for pigs. Ann Rech Vet 15:287-298. 
Tauson R. 1998. Health and production in improved cage designs. Poult Sci 77:1820-1827.

Taylor GB. 1972. One man's philosophy of welfare. Vet Rec 91:426-428.

UEP. 2008. United egg producers animal husbandry guidelines for U.S. egg laying flocks. Atlanta: United Egg Producers (UEP).

Weary DM, Fraser D. 1995. Signalling need: costly signals and animal welfare assessment. Appl Anim Behav Sci 44:159-169.

Weary DM, Ross S, Fraser D. 1997. Vocalizations of isolated piglets: a reliable indicator of piglet need directed towards the sow. Appl Anim Behav Sci 53:249-257.

Wielebnowski NC, Fletchall N, Carlstead K, Busso JM, Brown JL. 2002. Noninvasive assessment of adrenal activity associated with husbandry and behavioral factors in the North American clouded leopard population. Zoo Biol 21:77-98. 